\title{
Antifungal, Nematicidal and Antioxidant Activity of the Methanol Extracts Obtained from Medicinal Plants
}

\author{
Dang Minh Chanh Nguyen · Dong-Jun Seo · Ro-Dong Park • Woo-Jin Jung*
}

Received: 3 January 2013 / Accepted: 14 June 2013 / Published Online: 31 December 2013

(C) The Korean Society for Applied Biological Chemistry 2013

\begin{abstract}
The nematicidal, antifungal and antioxidant activities of methanol extracts from six Vietnamese native medicinal plants were evaluated by various assays in vitro. Of the plant extracts tested, Terminalia nigrovenulosa was found to possess the highest activity when compared to the others. The leaves and bark of $T$. nigrovenulosa showed strong inhibitory activity against Meloidogyne incognita and Fusarium solani. The DPPH (1,1-Diphenyl-2picryl-hydrazyl) radical scavenging, reducing power and total antioxidant activities of $T$. nigrovenulosa bark were higher than that of the remainder plant extracts. Chitinase activity of these plants was also investigated using SDS-PAGE. The results obtained in the present study indicate that $T$. nigrovenulosa leaf extracts are the greatest potential source as nematicides and fungicides for the control of $M$. incognita and $F$. solani. In particularly, T. nigrovenulosa bark extracts could be used as a potential source of commercially viable levels of natural antioxidant.
\end{abstract}

Keywords Fusarium solani $\cdot$ medicinal plants $\cdot$ Meloidogyne incognita $\cdot$ methanol extracts $\cdot$ Terminalia nigrovenulosa

\section{Introduction}

The control of plant diseases depends primarily upon the application of chemicals. However the high costs, non-availability at the time of need and the hazards they pose as environmental pollutants discourage most potential users (Pandey et al., 2000;

D. M. C. Nguyen · D.-J. Seo $\cdot$ R. -D. Park · W. -J. Jung

Division of Applied Bioscience and Biotechnology, Institute of Environmentally-Friendly Agriculture (IEFA), College of Agricultural and Life Science, Chonnam National University, Gwangju 500-757, Republic of Korea

\section{M. C. Nguyen}

Western Highlands Agriculture Forestry Science Institute, 53 Nguyen Luong Bang Street, Buon Ma Thuot, Vietnam

*Corresponding author (W. -J. Jung: woojung@chonnam.ac.kr)
Elbadri et al., 2008; Harish et al., 2008). Hence, it has become important to identify alternative control strategies that are as effective as synthetic pesticides, safe for farmers, consumers, and the environment and are relatively easily available at a low cost (Fernandez et al., 2001). Several plants have more environmentally and toxicologically safe selective and efficacious nematicidal potential (Javed et al., 2006; Dawar et al., 2008). These pesticides are generally considered to be non-persistent under field conditions, as they are readily transformed by light, oxygen, or microorganisms into less toxic products. Therefore, fewer residues are expected from those products (Ujvary, 2001; Akhtar et al., 2008).

Medicinal plants can provide potential alternatives to the use of synthetic pesticides, because they degrade to non-toxic products, and have fewer side effects to non-target organisms and the environment. Additionally, such agents often act at multiple and novel target sites, thereby reducing the potential of plant-parasitic nematodes becoming resistant to it (Isman, 2000; 2006). Medicinal plants have been used in traditional medicine as diuretics, topical anti-inflammants, and haemostatics (Burt, 2004). Medicinal plants usually produce many natural products, such as phenols, flavonoids, quinons, tannins, alkaloids, saponins, sterols, and volatile essential oils. These secondary metabolites have various functions, including antimicrobial, insecticide and appetite suppressant properties (Wilson et al., 1997; Isman, 2000; Liu and Zhang, 2004; Mares et al., 2005; Soylu et al., 2006; Yazaki et al., 2008; Akhtar et al., 2008). Plants in the genus Terminalia, family Combretaceae, comprising of some 250 species, are widely distributed in tropical areas of the world (Fabry et al., 1998). A methanol extract of Terminalia arjuna bark showed nematicidal activity against Haemonchus contortus (Bachaya et al., 2009). Also, ethanol extract of T. chebula fruit was toxic to both Meloidogyne spp. and Cephelobus litoralis (Zia ul Haq et al., 2010).

In this study, we focused on 1) the initial assessment of the nematicidal and antifungal activity against the phytopathogenic nematode (Meloidogyne incognita) and fungi (Phytophthora capsici, Fusarium solani, Fusarium oxysporum and Rhizoctonia solani) and 2) the determination of antioxidant (DPPH $(1,1-$ Diphenyl-2-picryl-hydrazyl) scavenging, reducing power and total 
antioxidant) activity of methanolic extracts from six medicinal plants in vitro.

\section{Materials and Methods}

Materials. The six medicinal plants were purchased from Buon Ma Thuot market, a medicinal plant and herb shop in DakLak province, Vietnam. Phytopathogenic fungi were obtained from the Korea Agricultural Culture Collection (Korea). Meloidogyne incognita eggs and second-stage juveniles (J2) were extracted from infected cucumber roots in a growth chamber. All other chemicals were of analytical grade.

Extraction of medicinal plants. Six medicinal plants were extracted in $80 \%$ methanol at a ratio of $1: 5(\mathrm{v} / \mathrm{v}$, dry plant material/solvent) at $30^{\circ} \mathrm{C}$ with shaking at $150 \mathrm{rpm}$ for 7 days. The extracts were filtered and concentrated by a rotary evaporator (EYELA N-1000, Japan) to obtain a crude extract. The Terminalia nigrovenulosa leaves crude extract was diluted with water and was then extracted with $n$-hexane, followed by chloroform, ethyl acetate, and finally with $n$-butanol. Equal volumes of each solvent and crude extract solution were then mixed by shaking for $3 \mathrm{~min}$ in a separation funnel. The organic solvent layers were concentrated to dryness by rotary evaporation at $40^{\circ} \mathrm{C}$, and the water soluble fraction was freeze-dried.

Antifungal assays. Antifungal assays were performed as previously described (Soylu et al., 2006) with slight modifications. Samples were dissolved with several different concentrations. Fifty microliters of each concentration were loaded onto each paper disc and methanol was used as a control. The mycelial growth was measured at 3 days after inoculation. The inhibition percentage was calculated by using the formula as follow: Inhibition $(\%)=\left(\left(D_{b}-D_{a}\right) / D_{b}\right) \times 100$, where $D_{a}$ is the diameter of the growth zone in the experimental disc $(\mathrm{cm})$ and $D_{b}$ is the diameter of the growth zone in the control disc $(\mathrm{cm})$.

Nematicidal activity assays. A direct-contact bioassay was used to evaluate $M$. incognita egg hatch after treatment with the medicinal plant samples. Approximately 250 eggs in $1 \mathrm{~mL}$ of water and sample of each concentration were added to each well of a 24-well Microtest tissue culture plate. The plate was covered with the original solid lid and wrapped with Parafilm, and the samples were kept at room temperature $\left(25 \pm 1^{\circ} \mathrm{C}\right)$. Hatch inhibition was based on the number of hatched juveniles at 3 days after incubation, as observed under a light microscope $(\times 40)$. Approximately $250 \mathrm{~J} 2$ larvae in $1 \mathrm{~mL}$ of water and sample of each concentration were added to each well of a 24-well Microtest tissue culture plate to determine juvenile mortality caused by the plant extracts, and the samples were maintained at room temperature $\left(25 \pm 1^{\circ} \mathrm{C}\right)$. At $0,3,6,9$ and $12 \mathrm{~h}$ of incubation, dead and live nematodes were counted to evaluate mortality rates using a light microscope $(\times 40)$. J2 mortality was estimated according to the mean percentage of dead J2. Nematodes were considered dead when no movement was observed during 2 seconds after mechanical prodding (Cayrol et al., 1989). Treatments were replicated six times, and the experiment was repeated.

Chitinase activity assays. The $T$. nigrovenulosa bark was cut into $0.5-1.0 \mathrm{~cm}$ pieces and powdered using a mortar and pestle to obtain the T. nigrovenulosa powder. This powder was extracted with sterilize distilled water after $80 \%$ acetone dialysis. Chitinase activity was assayed by measuring the amount of the reducing end group GlcNAc ( $N$-acetyl- $\beta$-D-glucosamine), produced by colloidal chitin (Lingappa and Lockwood, 1962). To evaluate the active staining of chitinase, the crude enzyme mixed with equal volumes of loading buffer was loaded directly onto the gel. SDS-PAGE $12 \%(\mathrm{w} / \mathrm{v})$ was performed according to the method described by Trudel and Asselin (1989).

Antioxidant activity assays. The DPPH radical scavenging activity was determined according to the method of Blois (1958) and minor modifications (Nair et al., 2012). A methanolic solution of sample $(0.1 \mathrm{~mL})$ at various concentrations $(100,50,25,10$ and $5 \mu \mathrm{g} / \mathrm{mL}$ ) was mixed with in $1 \mathrm{~mL}$ of $0.2 \mathrm{mM}$ DPPH dissolved in methanol $(0.004 \%)$. The reaction mixture was incubated for 15 min at room temperature in the dark. The control contained all the reagents without the sample and was used as blank. The DPPH radical scavenging activity was determined by measuring the absorbance at $517 \mathrm{~nm}$ using spectrophotometer. Lower absorbance of the reaction mixture indicates higher free radical scavenging activity. The DPPH radical scavenging activity of the sample was calculated using the following formula: Inhibition $(\%)=\left(\left(\mathrm{A}_{0}-\mathrm{A}_{1}\right) /\right.$ $\left.A_{0}\right) \times 100$. Where $A_{0}$ is the absorbance of blank sample and $A_{1}$ is the absorbance of tested extract solution. Butylated hydroxytoluence (BHT) was also assayed for comparison.

Total antioxidant capacities of the sample was analysed according to the method of Prieto et al. (1999). The assay is based on the reduction of $\mathrm{Mo}(\mathrm{VI})-\mathrm{Mo}(\mathrm{V})$ by the extract and subsequent formation of a green phosphate/Mo(V) complex at acid $\mathrm{pH}$. In brief a $0.1 \mathrm{~mL}$ aliquot of the sample at various concentrations $(100,50,25,10$ and $5 \mu \mathrm{g} / \mathrm{mL})$ was mixed with $1 \mathrm{~mL}$ of the reagent solution $(0.6 \mathrm{M}$ sulphuric acid, $28 \mathrm{mM}$ sodium phosphate and $4 \mathrm{mM}$ ammonium molybdate). The tubes were capped and then incubated at $95^{\circ} \mathrm{C}$ for $90 \mathrm{~min}$. After samples were cooled to $25^{\circ} \mathrm{C}$, the absorbance was measured at $695 \mathrm{~nm}$ against a blank. The blank contained $1 \mathrm{~mL}$ of the reagent solution without the sample. The total antioxidant activity was expressed as the absorbance of the sample. The higher absorbance value indicates the higher antioxidant activity. Ascorbic acid was also assayed for comparison.

The reducing power of methanol extract was determined according to the method of Oyaizu (1986), as described by Sidduraju et al. (2002). The different concentrations of extract $(100,50,25$ and $10 \mu \mathrm{g} / \mathrm{mL})$ in $1 \mathrm{~mL}$ of methanol was mixed with phosphate buffer $(2.5 \mathrm{~mL}, 0.2 \mathrm{M}, \mathrm{pH} 6.6)$ and potassium ferricyanide $\left(\mathrm{K}_{3} \mathrm{Fe}(\mathrm{CN})_{6}\right)(2.5 \mathrm{~mL}, 1 \% \mathrm{w} / \mathrm{v})$. The mixtures were then incubated at $50^{\circ} \mathrm{C}$ for $20 \mathrm{~min}$. Aliquot $(2.5 \mathrm{~mL})$ of trichloroacetic acid $(10 \% \mathrm{w} / \mathrm{v})$ was added to the mixture, which was then centrifuged for $20 \mathrm{~min}$ at $3000 \times \mathrm{g}$. The supernatant of solution $(2.5 \mathrm{~mL})$ was mixed separately with distilled water $(2.5$ $\mathrm{mL})$ and $\mathrm{FeCl}_{3}(0.5 \mathrm{~mL}, 0.1 \% \mathrm{w} / \mathrm{v})$, and the absorbance level was 
measured at $700 \mathrm{~nm}$ using a spectrophotometer. Increased absorbance of the reaction mixture indicates increased reducing power. The reducing power of ascorbic acid was also determined for a comparison.

\section{Results and Discussion}

Screening of antifungal and nematicidal activity of six medicinal plants. Table 1 shown nematicidal and antifungal activity $(5 \mathrm{mg} / \mathrm{mL})$ from six medicinal plants and their chitinase activity. Briefly, of the six plant extracts, Cinnamomum cassia showed significant inhibitory activity against $M$. incognita and $R$. solani. The leaves and bark $T$. nigrovenulosa showed significant inhibitory activity against $M$. incognita and $F$. solani, whereas no activity was observed in the assay of the remainder of the extracts against $M$. incognita. The leaves and bark of $T$. nigrovenulosa also showed inhibitory activity towards only some of the fungi tested (Table 1). Therefore, the leaves of $T$. nigrovenulosa were subjected to further separation and subsequent testing against $F$. solani and $M$. incognita. The leaves of $T$. nigrovenulosa methanol extract treatment resulted in $0,43.6,66.0$ and $85.5 \%$ at $0,0.5,1.0$ and $2.0 \mathrm{mg} / \mathrm{mL}$, respectively after 3 day incubation against $F$. solani (Fig. 1A and C). The highest antifungal activity (91.8\%) with significant difference $(P \leq 0.05)$ was at $1 \mathrm{mg} / \mathrm{mL}$ concentration of ethyl acetate fraction compared to remainder fractions after 3 day incubation (Fig. 1B and D). The leaves of T. nigrovenulosa methanol extract treatment resulted in $0,20.0,35.8,70.0$ and $84.2 \% \mathrm{~J} 2$ mortality at $0,0.25,0.5,1.0$ and $2.0 \mathrm{mg} / \mathrm{mL}$, respectively after $12 \mathrm{~h}$ incubation against $M$. incognita (Fig. 2A). Also, hatch inhibition resulted in $23.3,31.7,60.8,73.3$ and $85.5 \%$ at $0,0.25$, $0.5,1.0$ and $2.0 \mathrm{mg} / \mathrm{mL}$, respectively after 3 day incubation (Fig. 2B). J2 mortality and hatch inhibition of $M$. incognita induced by ethyl acetate fraction was showed significant difference in treated concentrations (Fig. 3A and B). J2 mortality and hatch inhibition increased with increasing concentration, indicating that they were dependent on treated concentration. Various plant extracts have been reported to exert different levels of antifungal activity in vitro against phytopathogenic fungi, including thyme (Thymbra spicata subsp. stoechas), oregano (Origanum syriacum var. bevanii), rosemary (Rosmarinus officinalis), fennel (Foeniculum vulgare) and Phytophthora infestans (Soylu et al., 2006). The nematicidal activity of some plant preparations, including the activity of essential oils against Meloidogyne spp., has been demonstrated (Oka, 2000; Chitwood, 2002; Zasada et al., 2006; Wiratno et al., 2009). Meyer et al. (2006) reported that extracts of Plantago lanceolata and $P$. rugelii were toxic to $M$. incognita eggs and J2, with the $P$. lanceolata extract tending to have the most activity. The essential oils of the fruit and bark of these trees are used for treating chronic dysentery, sore throat, laryngitis, and haemorrhoids (WHO/WPRO, 1990).

Chitinase activity. Chitinases play an important role in plant defense mechanisms against fungal pathogens (Patil, 2000). Many plants produce chitinases, and other so-called pathogenesis proteins, to deal with stressful conditions such as wounding and pathogen attack (Collinge, 1993). In this study, the highest chitinase activity $(10.16 \mathrm{U} / \mathrm{mg}$ protein) was observed in $T$. nigrovenulosa bark (OD $595 \mathrm{~nm}$ ) and followed by T. nigrovenulosa leaves (5.72), C. cassia bark (2.24), S. juventas root (1.08), J. subtriplinerve leaves (0.59), and C. camphora bark (0.26) (Table 1). Chitinase isoforms of six medicinal plants was explored on the SDS-PAGE gel (Fig. 4). Briefly, C. camphora bark (CC) and J. subtriplinerve leaves (JS) exhibited one chitinase band (Ch4). No band was observed in $C$. cassia bark (CA). S. juventas root (SJ) exhibited three clearly defined chitinase bands (Ch2, Ch3 and Ch4). T. nigrovenulosa bark (TNB) exhibited one chitinase band (Ch1) whereas $T$. nigrovenulosa leaves (TNL) exhibited two chitinase bands (Ch2 and $\mathrm{Ch} 4)$.

Antioxidant activity of six medicinal plants. The study revealed that the total antioxidant activity of the extracts increased in line with their concentration. T. nigrovenulosa bark was found to have a higher capacity for antioxidant retention than the other six samples. The antioxidant activities of the crude extracts were in the order: T. nigrovenulosa bark $>C$. camphora bark $>C$. cassia bark $>J$. subtriplinerve leaves $>T$. nigrovenulosa leaves $>S$. juventas root $>$ G. uralensis root (Fig. 5). DPPH is a stable free radical and accepts an electron, or hydrogen radical, to become a stable diamagnetic molecule (Soares et al., 1997). It is a commercial

Table 1 Nematicidal, antifungal and chitinase activity obtained from six medicinal plants in vitro

\begin{tabular}{|c|c|c|c|c|c|c|c|}
\hline \multirow{2}{*}{ Plant species } & \multirow{2}{*}{$\begin{array}{c}\text { Part of } \\
\text { used plants }\end{array}$} & \multirow{2}{*}{$\frac{\text { Nematode }}{\mathrm{Mi}}$} & \multicolumn{4}{|c|}{ Fungi } & \multirow{2}{*}{$\begin{array}{c}\text { Chitinase activity } \\
\text { (U/mg protein) }\end{array}$} \\
\hline & & & Pc & Fs & Fo & Rs & \\
\hline Cinnатотит cassia & Bark & +++ & - & - & + & +++ & $2.24^{\mathrm{c}}$ \\
\hline Cinnamomum camphora & Bark & + & - & + & + & + & $0.26^{\mathrm{e}}$ \\
\hline Jasminum suptriplinerve & Leaves & - & - & - & - & + & $0.59^{\mathrm{de}}$ \\
\hline Glycyrrhiza uralensis & Root & - & ++ & + & + & + & - \\
\hline Streptocaulon juventas & Root & - & + & - & + & + & $1.08^{\text {cd }}$ \\
\hline \multirow[t]{2}{*}{ Terminalia nigrovenulosa } & Bark & +++ & + & +++ & ++ & + & $10.16^{\mathrm{a}}$ \\
\hline & Leaves & +++ & + & +++ & + & + & $5.72^{\mathrm{b}}$ \\
\hline
\end{tabular}

Mi: Meloidogyne incognita; Pc: Phytophthora capsici KACC 40157; Fs: Fusarium solani KACC 40384; Fo: Fusarium oxysporum KACC 40032; Rs: Rhizoctonia solani KACC 40111. - no activity, + slightly activity, ++ moderately activity, and +++ high activity. Chitinase activity values are the mean \pm SD based on 3 replicates. Values that are followed by the same letter are not significantly different according to Tukey's Studentized range test at $p \leq 0.05$. 
A

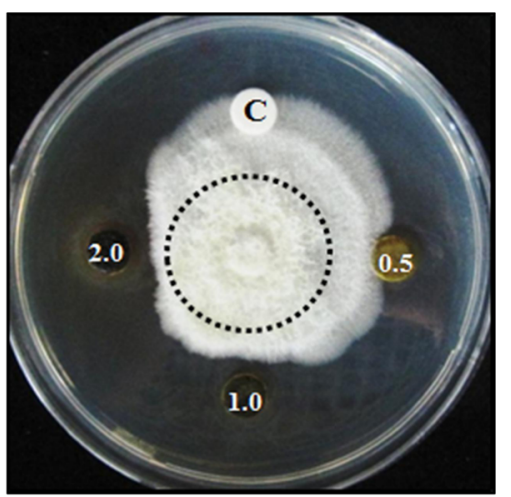

C

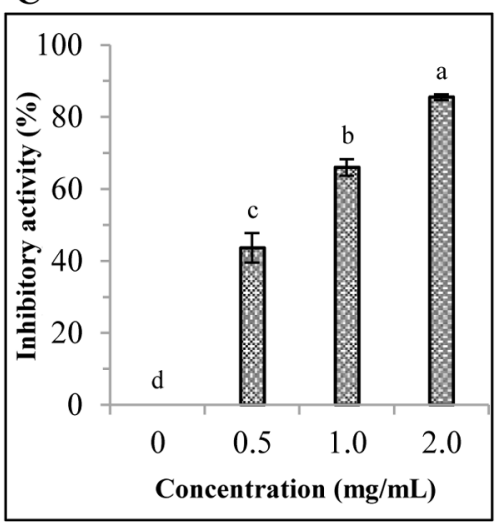

B

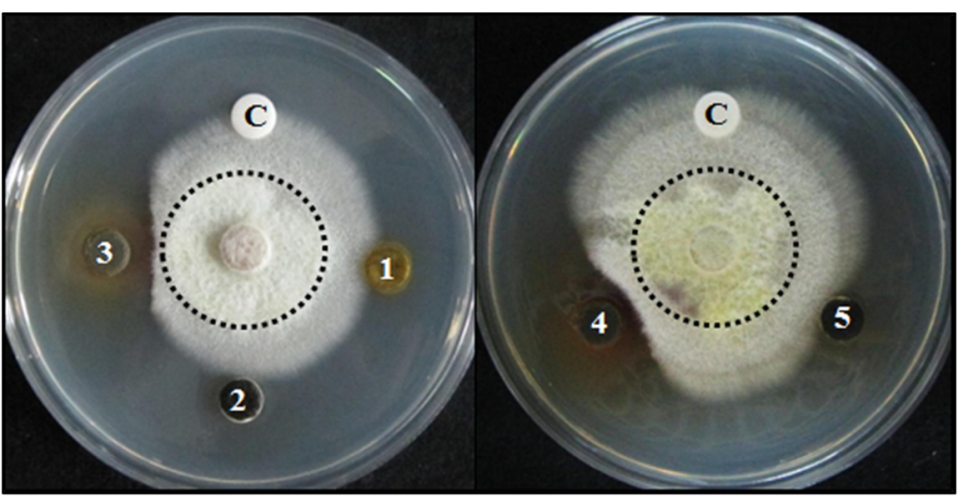

D

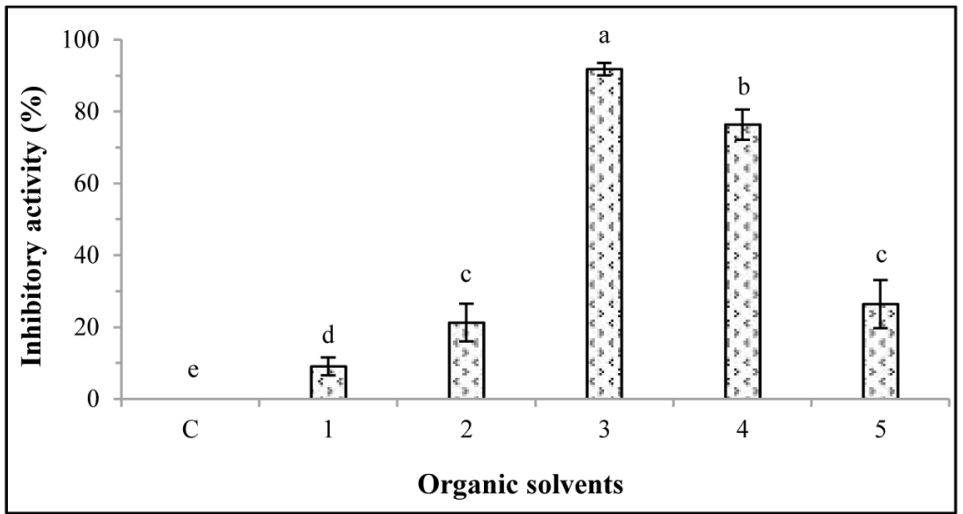

Fig. 1 F. solani mycelial growth inhibition induced by Terminalia nigrovenulosa leaves. (A and C) Methanol crude extract with different concentrations $(0,0.5,1.0$ and $2.0 \mathrm{mg} / \mathrm{mL}$ ). (B and D) Antifungal activity of $1.0 \mathrm{mg} / \mathrm{mL}$ concentration of each organic solvent obtained from TNL: Control (C; only methanol); n-hexane (1); chloroform (2); ethyl acetate (3); butanol (4); and distilled water (5).

$\mathbf{A}$

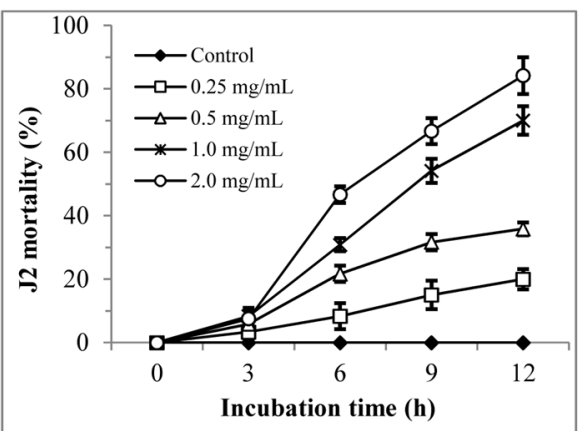

B

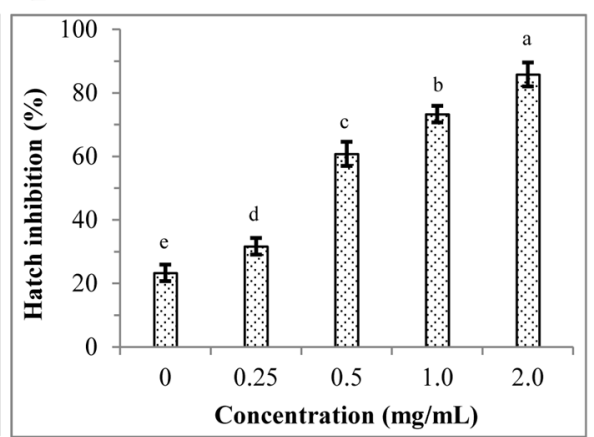

Fig. 2 Nematicidal activity of crude extract obtained from Terminalia nigrovenulosa leaves (TNL) at various concentrations ( $0,0.25,0.5$, 1.0 and 2.0 $\mathrm{mg} / \mathrm{mL}$ ). (A) $\mathrm{J} 2$ mortality of $M$. incognita after $0,3,6,9$ and $12 \mathrm{~h}$ of incubation; (B) hatch inhibition of $M$. incognita after 3 days of incubation.

oxidising radical, which can be reduced by antioxidants. The stable DPPH can be used to study the reaction kinetics of antioxidants, as well as to quantify and compare the free radical scavenging capacities of different antioxidants (Yu, 2001).

Fig. 6 was demonstrated the decrease in absorbance of DPPH radicals due to the scavenging ability of soluble solids in different concentration of crude extract. The DPPH radical activity of the medicinal plant extracts also increased with increasing concentration.
The highest DPPH radical scavenging activity $(94.8 \pm 2.5 \%)$ was observed in T. nigrovenulosa bark, higher than other crude extracts of medicinal plants at $100 \mu \mathrm{g} / \mathrm{mL}$. The DPPH radical scavenging activities of seven different samples of medicinal plants and BHT were increased in the order of BHT $>T$. nigrovenulosa bark $>C$. camphora bark $>C$. cassia bark $>T$. nigrovenulosa leaves $>J$. subtriplinerve leaves $>G$. uralensis root $>S$. juventas root. The result obtained in this investigation revealed that the DPPH radical 
A

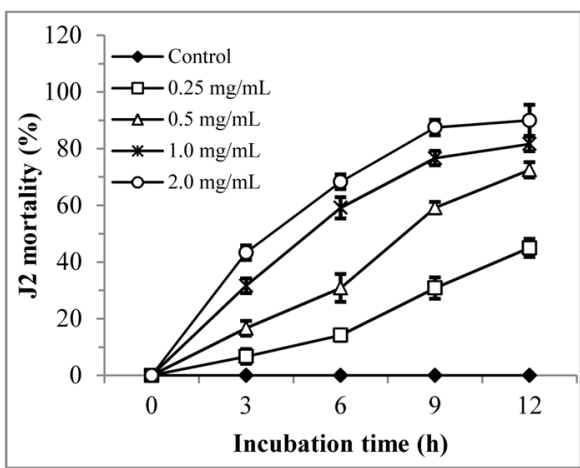

B

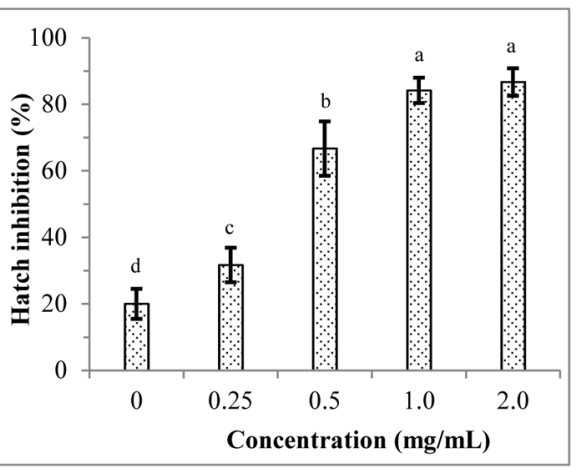

Fig. 3 Nematicidal activity of ethyl acetate fraction obtained from Terminalia nigrovenulosa leaves (TNL) at various concentrations $(0,0.25,0.5$, 1.0 and $2.0 \mathrm{mg} / \mathrm{mL}$ ). (A) $\mathrm{J} 2$ mortality of $M$. incognita after $0,3,6,9$ and $12 \mathrm{~h}$ of incubation; (B) hatch inhibition of $M$. incognita after 3 days of incubation.

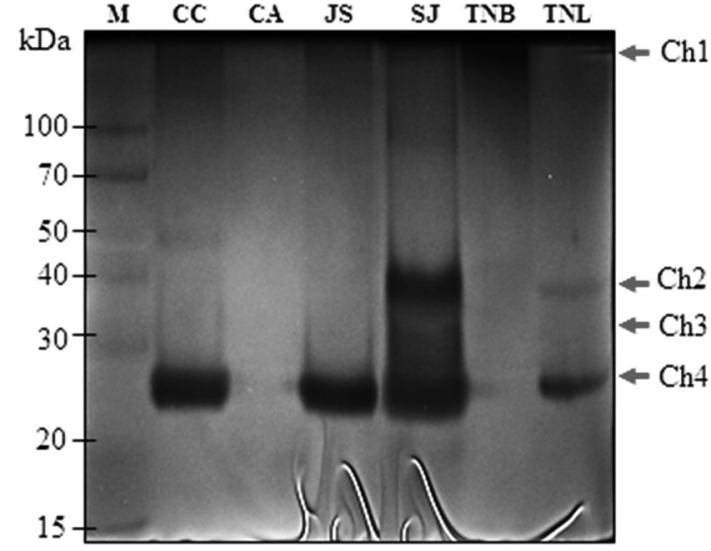

Fig. 4 Detection of chitinase isoforms in medicinal plant samples after $12 \%$ SDS-PAGE. A $30 \mu \mathrm{L}$ of crude protein in sterilized distilled water, after $80 \%$ acetone dialysis. M: standard protein marker; $\mathrm{CC}$ : $C$. camphora bark; CA: C. cassia bark; JS: J. subtriplinerve leaves; SJ: $S$. juventas root; TNB: T. nigrovenulosa bark; TNL: T. nigrovenulosa leaves. Chitinase isozymes 1, 2, 3 and 4 (Ch1, Ch2, Ch3 and Ch4).

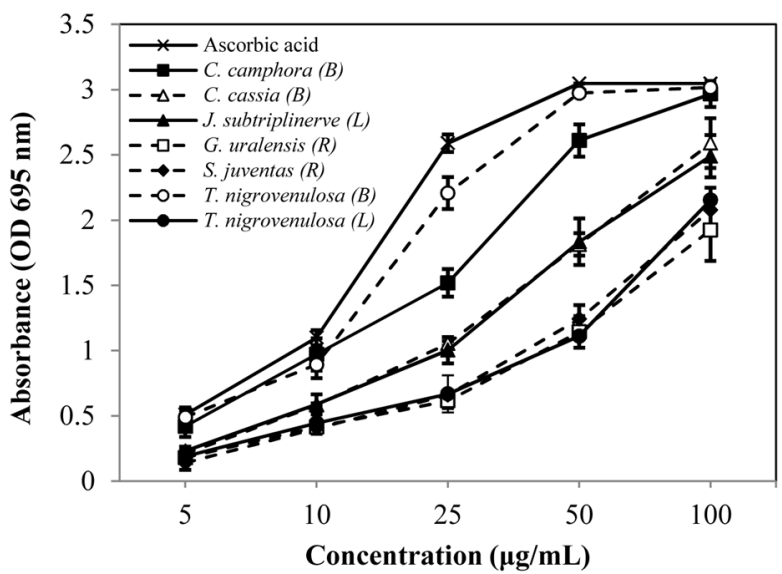

Fig. 5 Total antioxidant capacity of methanolic extracts of six medicinal plants. Results are means \pm SD of triplicate measurements.

scavenging activities of medicinal plants such as T. nigrovenulosa, C. camphora and C. cassia could be attributed to their hydrogen

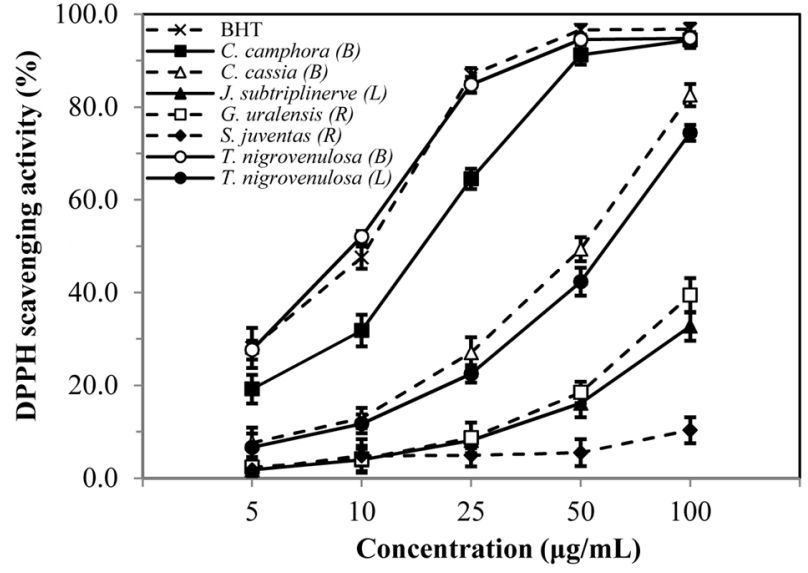

Fig. 6 Scavenging activity of methanolic extracts of medicinal plants against DPPH radical. Results are means \pm SD of triplicate measurements.

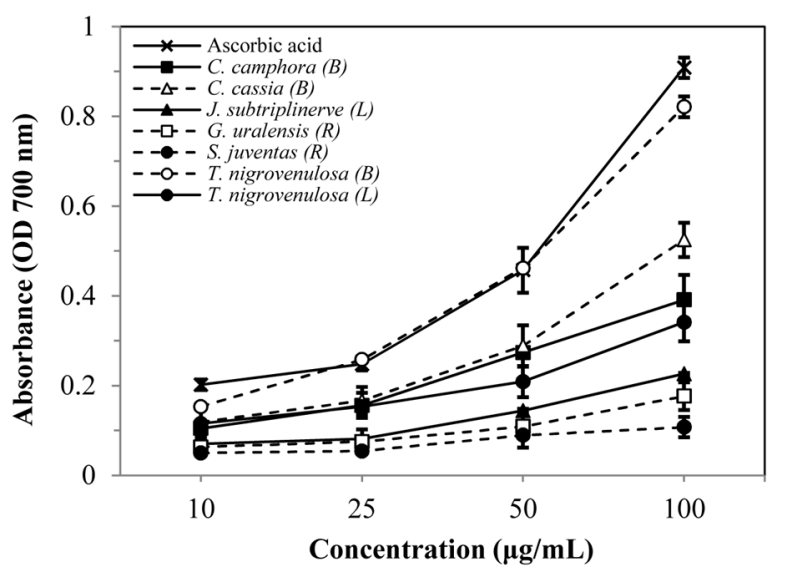

Fig. 7 Reducing power of methanolic extracts of medicinal plants. Results are means $\pm \mathrm{SD}$ of triplicate measurements.

donation abilities.

Reducing power is generally associated with the presence of reductones, which exert antioxidant action by breaking the free radical chain through donating a hydrogen atom (Duan et al., 
2007). Furthermore, Gupta and Prakash (2009) reported that $\mathrm{Fe}^{3+} /$ ferricyanide complex is reduced to the ferrous form by antioxidants, and can be monitored by measuring the formation of a navy blue colour at $700 \mathrm{~nm}$. The reducing power of the crude extracts of medicinal plants and the commercial compound ascorbic acid increased steadily with increasing concentration (Fig. 7). In this study, T. nigrovenulosa bark exhibited a higher reducing power compared to other medicinal plant extracts as shown in Fig. 7. The reducing powers of $T$. nigrovenulosa bark and ascorbic acid were 0.81 and 0.92 , respectively, at $100 \mu \mathrm{g} / \mathrm{mL}$. The reducing power of T. nigrovenulosa bark could be due to the di and monohydroxyl substitutions in the aromatic ring, which possess potent hydrogen donating abilities as described by Shimada et al. (1992).

Acknowledgments This study was supported by the Technology Development Program for Agriculture and Forestry, Ministry for Food, Agriculture, Forestry and Fisheries, Korea.

\section{References}

Akhtar Y, Yeoung R, and Isman MB (2008) Comparative bioactivity of selected extracts from Meliaceae and some commercial botanical insecticides against two noctuid caterpillars, Trichoplusia $n i$ and Pseudaletia unipuncta. Phytochem Rev 7, 77-88.

Bachaya HA, Iqbal Z, Khan MN, Jabbar A, Gilani AH, and Din IU (2009) In vitro and in vivo anthelmintic activity of Terminalia arjuna bark. Int Agric Biol 11, 273-8.

Blois MS (1958) Antioxidant Determinations by the Use of a Stable Free Radical. Nature 181, 1199-200.

Burt S (2004) Essential oils: their antibacterial properties and potential applications in foods-a review. Int J Food Microbiol 94, 223-53.

Cayrol JC, Djian C, and Pijarowski L (1989) Study on the nematicidal properties of the culture filtrate of the nematophagus fungus Paecilomyces lilacinus. Revue Nématol 12, 331-6.

Chitwood DJ (2002) Phytochemical based strategies for nematode control. Annu Rev Phytopathol 40, 221-49.

Collinge DB, Kragh KM, Mikkelsen JD, Nielsen KK, Rasmussen V, and Vad K (1993) Plant chitinases. Plant J 3, 31-40.

Dawar S, Sattar A, and Zaki MJ (2008) Seed dressing with biocontrol agents and nematicides for the control of root knot nematode on sunflower and okra. Pak J Bot 40, 2683-91.

Duan X, Wu G, and Jiang Y (2007) Evaluation of antioxidant properties of phenolics from litchi fruit in relation to pericarp browning prevention. Molecules 12, 759-71.

Elbadri GA, Lee DW, Park JC, Yu HB, and Choo HY (2008) Evaluation of various plant extracts for their nematicidal efficacies against juveniles of Meloidogyne incognita. J Asia-Pacific Entomol 11, 99-102.

Fabry W, Okemo PO, and Ansorg R (1998) Antibacterial activity of East African medicinal plants. J Ethnopharmacol 60, 79-84.

Fernandez C, Rodriguez-Kabana R, Warrior P, and Kloepper JW (2001) Induced soil suppressiveness to a root-knot nematode species by a nematicide. Biol Control 22, 103-14.

Gupta S and Prakash J (2009) Studies on Indian green leafy vegetables for their antioxidant activity. Plant Foods Hum Nutr 64, 39-45.

Harish S, Saravanakumar D, Radjacommare R, Ebenezar EG, and Seetharaman K (2008) Use of plant extracts and biocontrol agents for the management of brown spot disease in rice. BioControl 53, 555-67.

Isman BM (2000) Plant essential oils for pest and disease management. Crop Prot 19, 603-8.

Isman MB (2006) Botanical insecticides, deterrents, and repellents in modern agriculture and an increasingly regulated world. Annu Rev Entomol 51, $45-66$.
Javed N, Gowen SR, Inam-Ul-Haq M, Abdullah K, and Shahina F (2006) Systemic and persistent effect of neem (Azadirachta indica) formulations against root-knot nematodes, Meloidogyne javanica and their storage life. Crop Prot 26, 911-6.

Lingappa Y and Lockwood JL (1962) Chitin media for selective isolation and culture of Actinomycetes. Phytopathol 52, 317-23.

Liu YJ and Zhang KQ (2004) Antimicrobial activity of selected Cyathus species. Mycopathologia 157, 185-9.

Mares D, Romagnoli C, Tosi B, Andreotti E, Chillemi G, and Poli F (2005) Chicory extracts from Cichorium intybus L. as potential antifungals. Mycopathologia 160, 85-92.

Meyer SLF, Zasada IA, Roberts DP, Vinyard BT, Lakshman DK, Lee JK et el. (2006) Plantago lanceolata and Plantago rugelii extracts are toxic to Meloidogyne incognita but not to certain microbes. J Nematol 38, 333-8.

Nair VD, Panneerselvam R, and Gopi R (2012) Studies on methanol extract of Rauvolfia species from Southern Western Ghats of India - In vitro antioxidant properties, characterization of nutrients and phytochemicals. Ind Crop Prod 39, 17-25.

OKA Y (2000) Nematicidal activity of essential oils and their components against the root-knot nematode. Nematology 90, 710-5.

Oyaizu M (1986) Studies on product of browning reaction prepared from glucose amine. Jpn J Nutr 44, 307-15.

Pandey R, Kalra A, Tandon S, Mehrotra N, Singh HN, and Kumar S (2000) Essential oils as potent sources of nematicidal compounds. J Phytopathol 148, 501-2.

Patil RS, Ghormade V, and Deshande MV (2000) Chitinolytic enzymes: An exploration. Enzyme Microb Technol 26, 473-83.

Prieto P, Pineda M, and Aguilar M (1999) Spectrophotometric quantitation of antioxidant capacity through the formation of a phosphomolybdenum complex: specific application to the determination of Vitamin E. Anal Biochem 269, 337-41.

Shimada K, Fujikawa K, Yahara K, and Nakamura T (1992) Antioxidative properties of xanthan on the auto oxidation of soybean oil in cyclodextrin emulsion. J Agric Food Chem 40, 945-8.

Sidduraju P, Mohan PS, and Becker K (2002) Studies on the antioxidant activity of Indian Laburnum (Cassia fistula L.): a preliminary assessment of crude extracts from stem bark, leaves, flowers, and fruit pulp. Food Chem 79, 61-9.

Soares JR, Dinis TCP, Cunha AP, and Ameida LM (1997) Antioxidant activity of some extracts of Thymus zygis. Free Radic Res 26, 469-78.

Soylu EM, Soylu S, and Kurt S (2006) Antimicrobial activities of the essential oils of various plants against tomato late blight disease agent Phytophthora infestans. Mycopathologia 161, 119-28.

Trudel J and Asselin A (1989) Detection of chitinase activity after polyacrylamide Gel Electrophoresis. Anal Biochem 178, 362-6.

Ujvary I (2001) Pest Control Agents from Natural Products In Handbook of Pesticide Toxicology, (2nd ed). Academic Press, USA.

WHO/WPRO (1990) Medicinal plants in Vietnam. Institute of Materia Medica, Vietnam.

Wilson CL, Solar JM, AEl Ghaouth, and Wisniewski ME (1997) Rapid evaluation of plant extracts and essential oils for antifungal activity against Botrytis cinerea. Plant Dis 82, 204-10.

Wiratno, Taniwiryonoc D, Van-Den-Berg H, Riksen JAG, Rietjens IMCM, Djiwanti SR et al. (2009) Nematicidal activity of plant extracts against the root-knot nematode, Meloidogyne incognita. Open Nat Prod J 2, 7785.

Yazaki K, Sugiyama A, Morita M, and Shitan N (2008) Secondary transport as an efficient membrane transport mechanism for plant secondary metabolites. Phytochem Rev 7, 513-24.

Yu L (2001) Free radical scavenging properties of conjugated linoleic acids. $J$ Agric Food Chem 49, 3452-6.

Zasada IA, Klassen W, Meyer SLF, Codallo M, and Abdul-Baki AA (2006) Velvetbean (Mucuna pruriens) extracts: impact on Meloidogyne incognita survival and on Lycopersicon esculentum and Lactuca sativa germination and growth. Pest Manag Sci 62, 1122-7.

Zia ul Haq M, Ahmad M, and Akhter M (2010) Nematicidal activity of selected flora of Pakistan. Pak J Bot 42, 2119-23. 